\title{
Africa must come on board the genomics bandwagon
}

\author{
TEMIDAYO O. OGUNDIRAN
}

\begin{abstract}
With the completion and the success of the unraveling of the human and some nonhuman genetic codes comes the optimism that science, once again, is at the threshold of transforming human existence in an unprecedented way. The sequencing of the human genome with the science and technology by which it occurs is seen as a potential gateway to man's final conquest of most of the health and health related disorders that have for long plagued the human race.
\end{abstract}

While some developing nations like Cuba, Mexico and India have taken the initiative to be major players in the genomics arena by exploring its potentials towards enhancing improved quality of life for their citizens, the majority of others, especially in Africa, still occupy the spectators' seat. If this apparent lukewarm attitude continues, it implies that the present dependence on the developed nations as remote beneficiaries of gains of scientific breakthroughs will persist. It also means that the expectation that genomics should, among other benefits, re-dress the inequalities of access to health care between the rich and poor nations may be a mirage for a long time to come.

The expected benefits from the human genome project and genomics technologies are fascinating and hold the ace for improving the standards of living of the African people. However, these expectations are futuristic, time-dependent and capital intensive. They require commitments of national governments to policy re-orientation about research and development, strategic planning, resource mobilization, priority setting; and establishing, promoting and sustaining enabling environments for scientific and technological breakthrough. No doubt, there is dire need for assistance from the developed and the frontline developing nations in this regard. However, great initiatives and deep commitments to making significant scholarly contributions to the advancement of biotechnology and its potentials in the near future must come from within.

\section{Background}

The Human Genome Project, straddling the close of the 20th and the beginning of the $21^{\text {st }}$ centuries, is at the threshold of changing human thinking both in the way we look at the past and in the way we view the future. Genomics has the potential to unravel the mystery of past existence, modify our understanding of present events and redirect our focus on things that enhance the future good of humanity. Though its applications and uses appear to be more direct to medicine and human health, it has the potential to transform human civilization beyond the confines of biomedicine. The discovery of antibiotics in the early part of the last century marked the beginning of the march towards the conquest of infectious diseases resulting in total eradication of some and complete control of others, especially in the developed world. Genomics is to this century what infectious disease and discovery of antibiotics were to the last. ${ }^{1}$ 
The potentials of genomics, however, transcend those of antibiotics in that it holds promises to revolutionize our knowledge about the management and control of both infectious and non-infectious diseases.

Of particular importance is the relevance of genomics and its tools to narrowing the health gap between rich and poor nations and enhancing reasonable access to simple, cheap and effective health services in developing countries. ${ }^{2}$ In view of this potential, calls have been made to less developed countries of the world not to stand by in the mistaken impression that genomics is of and for the developed world. Some developing nations like Cuba, Mexico and India have risen up to the challenge and have taken the initiative to be major players in the genomics arena by exploring its potentials towards enhancing improved quality of life for their citizens. ${ }^{3}$ However, many countries of Africa excluding South Africa, Egypt and perhaps one or two others, still lag behind. It is imperative that African nations emulate the examples of the developing countries that have assumed frontline positions in genomics.

In a foresight study of the ways in which genomics is likely to affect the third world, Daar et al identify top ten technologies for improving health in developing countries. ${ }^{4}$ Prominent on the list is the use of genomics biotechnology to confront the menace of infectious diseases through development of simple and affordable diagnostic methods; development of vaccines and efficient delivery systems; and identification of new antimicrobials and drug targets. The list also includes application of genomics to improving agricultural yields and enhancing a clean environment. Pang and many others support the view that genomics would enhance the control of infectious and non-infectious diseases on a global scale. Further more, sequencing of the rice genome offers opportunities for improved yield and more nutritious value for the three billion people, mainly in the developing world, who depend on rice as their staple diet. ${ }^{5}$ These and many others express the common view that genomics could be a veritable tool for improving health and living standards in developing countries. This paper focuses on developing African nations using Nigeria with immense potentials as a prototype, not only to contribute to the genomics breakthroughs, but also to reap from its windfall. It explores why African nations should not lag behind other developing nations of the world in exploring the genomics landscape and considers the process towards achieving this drive.

\section{Discussion}

\section{The situation: Nigeria as a prototype}

With a population of 130 million people, an annual growth rate of about $2.8 \%$, more than 250 ethnic groups and over 300 dialects and languages, Nigeria is the most populous and most culturally diverse black nation in the world. One in two West Africans and one among six Africans is a Nigerian. The country emerged from the ruins of a civil war in the late sixties and early seventies to a dawn of a new era signaled by the discovery of abundant petroleum oil reserve in the Niger delta. This discovery resulted in total abandonment of the agriculture sector which had hitherto been the mainstay of the economy, and an over-dependence on the capital-intensive oil sector, which now provides almost all of foreign exchange earnings. What began as an "oil boom" with a lot of potentials for development and a strong foreign 
exchange earning capacity and economic base for the country later became an albatross which may now be looked back upon as an "oil doom". A combination of failure to further develop other sectors of the economy, over-dependence on petrodollar, military mis-adventure in power with consequent destruction of the moral fabrics of the society and an enthronement of systemic corruption, mismanagement, inflation, political unrest and ethno-religious conflicts, has produced a state with a GDP per capita income of about US \$300.

However, except for a few setbacks which are reminiscent of a long period of military rule, the return of participatory democracy in Nigeria in the past six years has brought about significant re-orientation of the body polity. The relatively stable political climate should provide a springboard for an all round development and an incentive for investment in science and technology. Though the potential gains of genomics technology are still a long way to reach even in the technologically advanced countries of the west, it is imperative for resource- poor and less technologically advanced nations to join forces with others now. They must not wait till the gains become tangible, otherwise those benefits would be out of their reach and the present status quo of disparity in distribution of the gains of science and technology in health would remain, and even worsen. Nigeria and the whole of Africa stand to benefit in many aspects especially in health, agriculture and the environment.

\section{Health profile}

Infant and child mortality rates are basic indicators of the socioeconomic development of a country and the quality of life of its people. Specifically, infant mortality (which is the probability of dying before the first birthday) in Nigeria is highest when compared with some countries from different geographic zones of the world (Figure 1). In the period from 2000 to 2005, while the infant mortality rates in most of these countries (except South Africa and Iran) have fallen consistently, the rate increased from 74.18 to 98.8 per 1000 live births in the same time period in Nigeria. ${ }^{7}$ The high prevalence of communicable but preventable diseases like malaria, dysentery, pneumonia and measles contributes significantly to high childhood mortality and morbidity rates in Nigeria. Besides these are other infectious diseases like typhoid, amoebiasis, guinea worm, helminthiasis, tuberculosis and hepatitis which also cause considerable mortality and morbidity in both adults and children. While most of these communicable diseases have been eradicated or controlled in the developed and some developing countries, they still constitute a major health hazard in Nigeria and most countries in sub-Saharan Africa.

Moreover, a significant proportion of Nigerians have genetic disorders such as sickle cell anaemia and glucose 6-phosphate dehydrogenase deficiency or their traits. In addition to the burden posed by infectious and genetic diseases is the epidemiological transition which Nigeria, like many other developing countries is undergoing. ${ }^{5}$ Hypertension and diabetes presently affect about $10 \%$ and $2.75 \%$ of the population respectively, but prevalence rates of these diseases are rising. ${ }^{8}$ The incidence of breast cancer appears to have stabilized and is perhaps declining in some western countries, whereas it has been increasing in those societies that hitherto had a low incidence including Nigeria. ${ }^{9}$ Regrettably, little or no attention is given to these time-dependent fatal diseases some of which are hinged on lifestyle and behaviour. 


\section{Figure 1}

Infant Mortality Rate in some Selected Coun tries

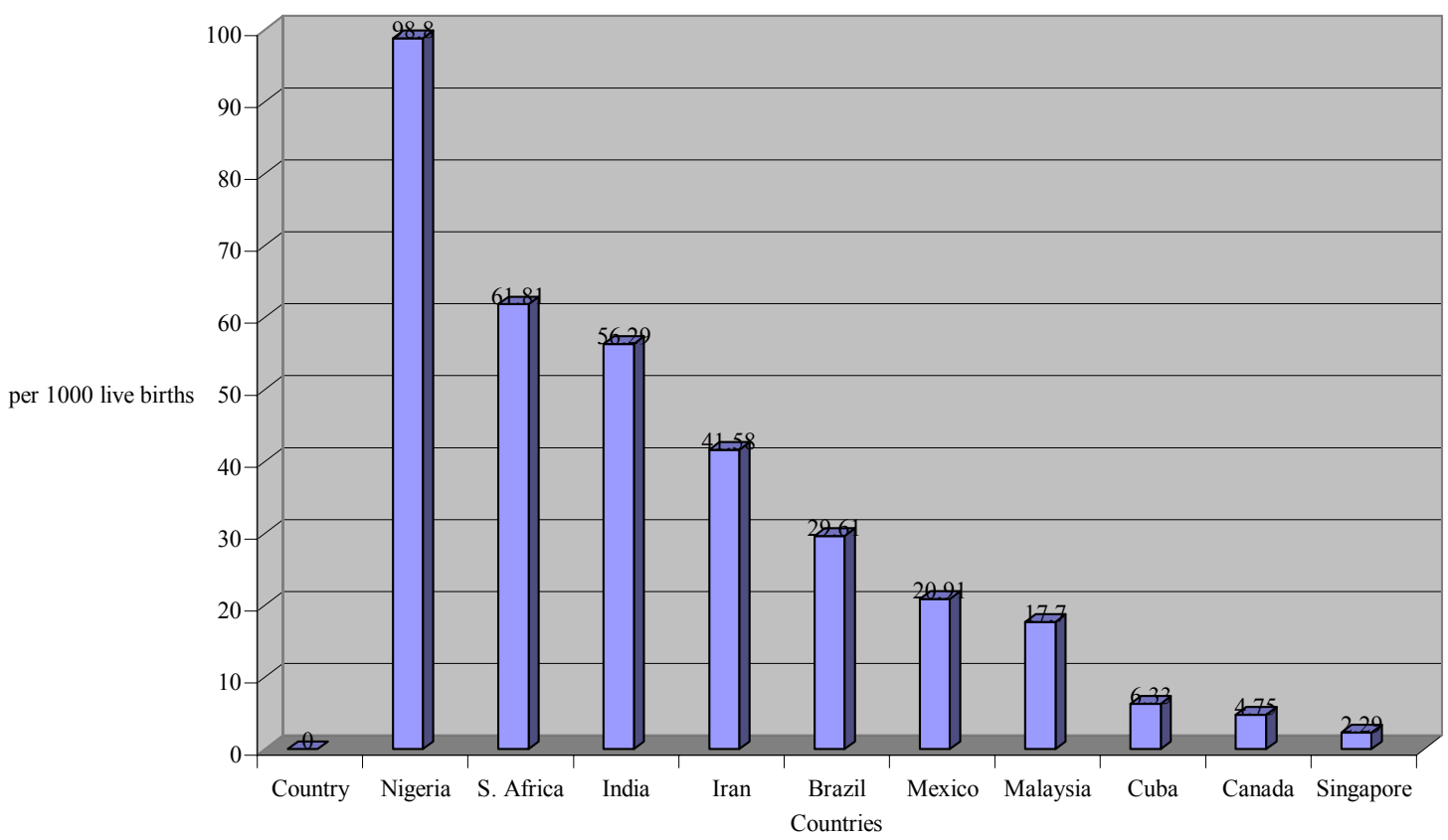

\section{How genomics (proteomics, pharmacogenomics etc) might help the situation}

One of the promising benefits of the knowledge of human and non-human animal genomes is the application of technology to enhance the health of humans in both the developed and the developing worlds. As is shown above, the major causes of morbidity and mortality in Nigeria and most African countries are preventable, treatable and controllable. Most of these diseases present a formidable prevention, diagnosis and treatment triad. Apart from an efficient public health system and a positive attention to personal and environmental hygiene by the people, the only other significant means of curtailing the spread of these communicable diseases is an effective vaccination programme. Hitherto the different vaccination programmes and efforts in Nigeria for example, are far from being universally successful, adequate or effective. In spite of the fact that most of the vaccines are supplied free by donor nations and agencies, and are provided free to the public, some other extenuating factors like difficulty with maintaining an unbroken cold chain, non-oral route of administration and cumbersome dosing schedules militate against effective vaccination against the killer diseases. It is hoped that advancements in genomics and DNA based vaccine production would result in developing vaccines whose availability, storage and administration will bypass or overcome most of the hurdles hitherto encountered in immunization programmes. The prospect of utilization of plant science as a new vehicle for vaccine delivery holds good promise for Nigeria and the whole of Africa. ${ }^{10} 11$

Vector control through genetic modification and biochemical targets offers a promising approach in the battle for conquest of many diseases. At the Africa Human Genome Initiative Conference in South Africa in March 2003, Gordon Dougan, 
Director, Centre of Molecular Microbiology and Infection, Imperial College, United Kingdom, told participants who came from African countries: "Don't be hypnotised by technology, vaccines can be produced with relatively simple technology within five years.." Talking about developing vaccine against typhoid infection, he said: "There is no great mind boggling technology involved in this - it is relatively simple, so don't be scared of it.",12

Another major health hurdle is the diagnostic difficulties that clinicians and laboratory scientists encounter which make pathogen isolation an arduous task and which invariably delay institution of definitive drug therapy. The new biotechnology would facilitate development of simple, rapid and high precision diagnostic tools which would be available and applicable in the developing countries where they are most needed and where there is a ready market for them. Presently most new drug research and development are done in western nations and of all the 1233 drugs in the market between 1975 and 1999, only 13 were for diseases that are prevalent in the tropical countries. ${ }^{13}$ Through pharmacogenomics and with the increasing knowledge of the genetics of diseases and the genetic variations among groups of peoples, it should be possible to develop new drugs against many tropical diseases. Such drugs would be selective, efficacious, safe and better tolerated. Moreover, in a continent where trauma and thermal burns with large wounds from vehicular and fire accidents are rampant, biotechnology holds a promise for developing living cultured skin for managing the wounds. ${ }^{14} 15$

\section{Agricultural profile}

Farming remains a major income-generating occupation of many urban and rural dwellers in Africa. Many people engage in farming as a means of supplementing their meager income or providing food for their households and extended family members; while some others practice farming as a commitment to a long family tradition. Apart from having a favourable agro-climatic condition, it is estimated that Nigeria has a cultivable land area of 71.2 million hectares and an agricultural population of about 38 million people. This agricultural population is said to be 3 times the combined agricultural populations of Japan, USA and the UK. ${ }^{16}{ }^{17}$ Arguably more than $50 \%$ of Africa's active labour force is employed in agriculture. As alluded to above, Nigeria had been a world class producer of cash crops such as cocoa, palm produce, rubber and groundnut before the oil boom era of the 1970s.

In spite of this potential of becoming an agricultural giant in Africa, Danladi Kuta, a molecular biologist with the Sheda Science and Technology Complex, Abuja, Nigeria says Nigeria remains an agricultural dwarf and a low-income food-deficit country. ${ }^{17}$ Nigeria does not produce enough to feed its teeming population and imported food products worth millions of dollar in the last decade. Many wage earners spend most of their income on food alone. According to him, the current agricultural growth rate of $4.5 \%$ is far less than the $10 \%$ mark which is the minimum that is required to meet the increasing food demand of the nation. The reasons for the country's low agricultural productivity include the fact that the bulk of agricultural production is done by resource-poor rural farmers who plant crop varieties with poor yield and that can not tolerate water stress or resist insect pests and infestation with nematodes. ${ }^{17}$ Other factors include poor weed control strategies, post-harvest storage constraints and largely a non-mechanized farming system. 


\section{How genetic modification (GM) technology might help the situation}

Jacques Diouf, Food And Organization Director-General, states that "biotechnology offers opportunities to increase the availability and variety of food, increasing overall agricultural productivity while reducing seasonal variations in food supplies." $\mathrm{He}$ states further that "the effective transfer of existing technologies to poor rural communities and the development of new and safe biotechnologies can greatly enhance the prospects for sustainably improving agricultural productivity today and in the future" 18 Apart from the developing countries of Africa, even in the developed countries of the world, there is increasing demand for more and better quality food as the world population increases and the quantity and quality of arable land mass diminish as a consequence of overcrowding, industrialization, land degradation by over tillage and organic pollutants; all leading to "an increasingly fragile natural resource base" that will be incapable of providing enough food for the growing world population. $^{19}$

Though there is a global need for improved food quality, the situation becomes more precarious in Africa where most under-five deaths are associated with malnutrition. I agree with Kuta that an investment in agricultural biotechnology would lead to a mitigation of the constraints that presently hinder bumper yields through development of herbicide-tolerant transgenic crops, improved crop varieties that can tolerate water stress and crops developed with resistance genes to insect pests, nematodes and viruses. According to him, glyphosate is a safe and non-residual herbicide, but it is non-selective and destroys green plants; hence it has to be sprayed before or just after planting the crops thus limiting weed control to the initial phase of cropping. However, through GM technology, glyphosate-tolerant soybeans and corn are now grown in some developed countries. African farmers would benefit from the application of similar technology to locally produced crops like rice, beans and guinea corn which are major food crops across the continent. Cowpea, cassava and yam are major staple food sources, which are plagued by insect pests, viruses and nematodes. Incorporation of pest resistance genes into their genomes is one way of improving their survival and enhancing good yield. Further more, development of cyanogen-free transgenic cassava and incorporation of gluten genes into cassava will lead to improved cassava quality as well as cutting the present foreign exchange spending since cassava flour could be substituted for imported flour used in the baking industry. ${ }^{17}$

\section{Environment and bioremediation}

The principle of bioremediation has wide applications in developing countries as a cheap and effective method for cleaning up the environment through the use of natural and genetically engineered microorganisms. ${ }^{4}$ This technology is of particular benefit to Nigeria where sewage disposal, water pollution and petro-chemical oil spillage with consequent destruction of natural plant and marine life especially in the Niger Delta are major health hazards. In Brazil, the Federal University of Santa Catarina and Petrobrás, the Brazilian national oil company jointly address the degradation of benzene, toluene, ethylbenzene and xylene (BTEX) from gasoline spills by phytoremediation, a bioremediation process that uses plants. ${ }^{20}$ By investing in biotechnology, the Nigerian government would be providing the initiative for the 
several multi-national oil companies operating in the Niger Delta to team up with local universities in tackling the huge problem of environmental pollution through bioengineering.

\section{The process}

\section{Change of mindset}

The initiatives for change have to come from within Africa and not only from without. The hitherto lukewarm attitude of African governments to research and development has to give way to informed commitment by governments and all stakeholders. Proactive steps and critical policy shifts should move the continent from being a recipient of technology end-products (from the west) and from being a predominantly consumer economy to a technologically productive continent. If the developed and the up-coming nations of the world have achieved significant momentum in biotechnology and are tapping its benefits through concerted efforts of both their governments and peoples, the process cannot be otherwise for Africa.

The process should begin by learning from the examples of frontline developing countries like Mexico and India, by enacting policies that are backed up with legislative power, and by commitment to building a robust infrastructure that is immune to political control and manipulation. Governments must provide conducive environments, tax incentives, and favourable land lease agreements for local and foreign investors that show interest in investing in biotechnology. As is the case in South Korea, patent protection incentives should be given to scientists and entrepreneurs who venture to invest in biotechnology. ${ }^{21}$

\section{Comprehensive education program}

There is a long phase between scientific and technological breakthroughs and their final consumable end products. In this regard a well informed and motivated citizenry is a great asset. Public understanding is very important especially with regards to information about the eventual end products of genomics and biotechnology, for example, the cultural acceptability of GM food. Adequate education programmes are needed at all levels to enhance public understanding of the concepts of biotechnology, genomics, genetic engineering, genetic testing, genetic research, genetically modified food etc. This can be achieved through appropriate utilization of different educational programmes, schools, public fora, the news media, NGOs etc. Needless to say that molecular biology and genetics should be an integral part of the training of physicians, nurses, other health care professionals and biochemical scientists.

\section{Building and strengthening capacity for biotechnology}

The success or failure of a scientific innovation or endeavour is critically dependent on many factors including the comprehensiveness of the capacity that is acquired prior to inception of the project and the mechanism that is put in place for lubricating and strengthening the system for on-going efficient and satisfactory performance. Presently, pharmaceutical and related industries in Nigeria and most African countries do not possess the biotechnological capabilities of the developed world. For example, 
none of the national crop research institutes in Nigeria has the appropriate facilities and the critical mass of scientists for the application of GM technology except at the International Institute of Tropical Agriculture (IITA) which is presently developing transgenic banana/plantain, cowpea, and cassava. ${ }^{17}$ Therefore, establishing a solid biotechnology base for Africa requires equipping academic centres and research institutes with infrastructure for molecular science and technology. Human capacity building would be enhanced by establishing scholarships for undergraduates who are willing to pursue a career in molecular sciences and by providing funding for graduate students to do research in molecular biology, biotechnology, bioinformatics etc. Governments should be committed to increasing spending on research and development, increasing education budgets at all levels, and prioritizing the teaching and learning of mathematics, the sciences and technology as was the case in India immediately after independence in $1947,{ }^{22}$ and as is presently done in South Africa. Moreover, other African nations should emulate the example of South Africa in developing and articulating their biotechnology sector to address their specific health needs. $^{23}$

African governments should establish a network of researchers within their countries, coordinated regionally or nationally, and launch specific biotechnology development targets periodically. Moreover, governments should court the good will of frontline developing countries that have made significant progress in the field and seek to sponsor academics to fellowship programmes in such countries and also establish exchange of researchers with them. Academic institutions should be encouraged to pursue collaborations between local and foreign scientists both from developed and developing countries. Governments should also midwife industry-institution partnerships between the universities or research institutes and pharmaceutical and allied industries.

\section{Fostering regional collaborations within African nations}

On 3rd May 2004, the Nigerian National Biotechnology Development Agency in Abuja, Nigeria, launched the Nigerian Agriculture Biotechnology Project (NABP) and the West African Biotechnology Network (WABNET). ${ }^{24}{ }^{25}$ According to the Nigerian Minister of Science and Technology, the project would help to raise the effectiveness and efficiency of bio-resources and biotechnology in Nigeria and West Africa; and promote economic growth, ensure sustainable use of the natural resource base, enhance the health, environmental, industrial and agricultural development in the subregion. This kind of collaboration between Nigeria and its neighbours is akin to the Asia-Pacific International Molecular Biology Network (IMBN) and European Molecular Biology Organization (EMBO). More of such collaboration is needed in Africa in molecular biosciences and biotechnology. It encourages cross fertilization of ideas and presents a common front for tackling health and health-related problems that are peculiar to the sub-region and continent. Similarity of circumstances would make these programmes more relevant and cost effective. ${ }^{25}$ Given the strategic position, the human and economic potentials of Nigeria in the West African subregion, this could begin a process of diversifying its economy by exporting biotechnological assistance to neighbouring countries that would in turn obtain it cheaper than they would from developed nations. 


\section{Resource mobilization}

The foreseeable gains of genomics are not reliant on biotechnology alone, but also on politics and resources. ${ }^{26}$ Resource mobilization for biotechnology involves a reprioritization of national interests and programmes and a re-distribution of the available resources to high priority and promising areas. Nigeria runs a wasteful political system that spends much resource to service and maintain the different arms and functionaries of government. The civil service is too unwieldy and unproductive to justify the huge wage bill that the different tiers of government incur every month. It is time Nigerians and other Africans realized that politics and civil service are no longer avenues for sharing the so called "national cake", and that remuneration should be based on productivity and relevance.

Justice requires that priority funding is given to programmes that benefit the continent the most. Traditionally, a large percentage of budgetary allocation goes to many unproductive services, an example of which is defense. The defense budget in Nigeria and perhaps in many African countries supports a retinue of highly redundant military personnel some of whom are highly qualified but underutilized in productive service to the country. No doubt, the Nigerian military consists of a crop of young, brilliant and science-oriented officers that could be linked up with academic institutions in the country with a mandate to produce a biotechnology revolution for the country. In addition, it is time rich and affluent Africans were re-orientated to embrace the culture of supporting science and health related research. Philanthropic investments and endowment of chairs in biotechnology in academic institutions by well-placed and affluent Africans might be a better way of investing in the future of the continent. Besides all these, apart from the initial lump sum as take-off grants, governments should commit sizeable percentages of their annual budget allocations to the biotechnology industry.

\section{Enforcement of the rule of law}

The bane of most developing countries of the world is political instability and corrupt leadership. A stable polity and an accountable and responsive government are the minimum requirements for development and for attracting foreign investors. The present political stability in Nigeria, Ghana and many other countries of Africa coupled with the active involvement of their present leadership in the New Partnership for African Development (NEPAD), established to support economic and political reforms in Africa through peer review of one another's performance, is a positive development for the continent. What needs to be put in place is due ethical and legal process for establishing and enforcing appropriate regulatory standards for genomics research and mechanisms for ensuring financial prudence and fiscal discipline. Furthermore, both the public and private sectors should collaborate in common biotechnology ventures. The private profit-oriented partner provides the fiscal and entrepreneurial discipline and thoroughness that are often lacking in government run programmes, while the public component regulates and controls the profit driven private sector interests. Also important to consider under legal considerations are intellectual property rights and patent issues. Developed countries will be reluctant to share technologies with developing countries legal systems that do not entrench and enforce intellectual property rights. In many African countries, intellectual property rights are either non-existent or are grossly violated and so patent 
holders are reluctant to share technologies with these countries. This is a major impediment to realizing technology breakthrough in Africa and African governments and legal systems must address it forthwith.

\section{Ethical issues}

Genomics and biotechnology raise many complex ethical, legal, and social concerns and challenges which require that national bioethics policy be instituted to guide the development of the biotech industry and protect the interest of the people. International safety and ethical standards should be adapted in the context of local factors such as literacy level, socio-economic conditions, cultural practices and religious beliefs. Capacity building in bioethics should be pursued pari passu with the evolution of genomics science and technology by providing training for physicians, nurses, other health care professionals and biological scientists. Special training is required for research ethics review committee members to update them with developments in the ethics of genomics research, handling of genomics information and biosafety requirements. Genetically modified food is one novel outcome of biotechnology with the potential to dramatically address the present food crisis in many African nations. It has become such a vexing issue with many political undertones that some African heads of governments have openly declared their countries' rejection of GM food aids. ${ }^{27}{ }^{28}$ More often than not, most of these discussions are shaped and fueled by the opinions and writings of a few vocal and prominent individuals and/or organizations from inside but mostly from outside Africa. There is dire need for empirical qualitative and quantitative research to document people's perceptions and expectations about GM food and other potential future benefits of genomics revolution in Africa. Such research is required to provide basic knowledge about what the people actually want. It will also provide an opportunity to predict and proactively prepare for the social, cultural, religious and ethical implications of genomics to the African people.

\section{Conclusion}

The expected benefits from the human genome project and genomics technologies are fascinating and hold the ace for improving the standard of living of the African people. However, these expectations are futuristic, time-dependent and capital intensive. They require commitment of national governments to policy re-orientation about research and development, strategic planning, resource mobilization, priority setting, and establishing, promoting and sustaining enabling environments for scientific and technological breakthrough. No doubt, there is dire need for assistance from the developed and the frontline developing nations in form of information flow, developing educational capacity and technology transfer, but great initiatives and deep commitments must come from within. The time to begin is now as further delay would worsen the already existing gaps between the high and middle income nations on one hand and the low income nations on the other.

It should be acknowledged that biotechnology in its crude and traditional form is not new in Nigeria and other parts of Africa especially in some aspects of biology and agriculture. Moreover countries like South Africa and Egypt have advanced somewhat in modern biotechnology compared to others. However, there is the need to recognize and harness the revolutions and innovations that the knowledge of genomics has 
brought to molecular biology and biotechnology. Though genomics may not be the final solution to all the problems in which the developing countries are presently enmeshed, it might be a decisive and positive step towards solving most of their present and future health problems. In the words of Samuel Katz, "difficulties that present themselves now should not prevent us looking into future possibilities.",

\section{Acknowledgement}

The author is grateful to Nandini Kumar of Indian Council of Medical Research, New Delhi, India and Jerome Singh of Centre for the AIDS programme of Research in South Africa (CAPRISA), University of KwaZulu-Natal, Durban, South Africa, for their useful comments in preparing the final draft of this paper.

${ }^{1}$ Gerard S, Hayes M, Rothstein MA. On the edge of tomorrow: Fitting genomics into public health policy. The Journal of Law, Medicine \& Ethics 2002; 30(3):173-176

2 Singer PA, Daar AS. Harnessing genomics and biotechnology to improve global health equity. Science 2001;294:87-89

${ }^{3}$ Thorsteinsdottir H, Quach U, Martin DK, Daar AS, Singer PA. Introduction: promoting global health through biotechnology. Nature biotechnology, December 2004; 22 (Supplement): DC 3 - 7

4 Daar AS, Thorsteinsdottir H, Martin DK, Smith AC, Nast S, Singer PA. Top 10 biotechnologies for improving health in developing countries. Nature Genetics 2002;32:229-232

${ }^{5}$ Weatherall DJ. Genomics and global health: time for a reappraisal. Science 2003; 302: 597-599

${ }^{6}$ Pang T. The impact of genomics on global health. American Journal of Public Health 2002; 92 (7): 1077-1079

${ }^{7}$ CIA World Fact Book. Available at http://www.indexmundi.com/g/r.aspx?c=ni\&v=29 Accessed 23 November 2005

${ }^{8}$ Health Systems Development Project II. Federal Ministry of Health (FMOH) of Nigeria, Abuja, August, 2000

9 Adebamowo CA, Ajayi OO. Breast cancer in Nigeria. West Afr J Med. 2000; 19(3):179-91

${ }^{10}$ Langridge WH. Edible vaccines. Sci Am. 2000; 283 (3): 66-71

${ }^{11}$ Katz SL. Future vaccines and a global perspective. The Lancet 1997; 350(9093): 1767- 1770

12 Dougan G. Technology transfer to developing regions: Vaccinology as an example. In Genomics and society: The future health of Africa. Africa Genome Initiative Cairo Conference, March 2003

${ }^{13}$ World Health Organization. Genomics and world health. Report of the advisory committee on health research. Geneva: WHO, 2002. Available at http://whqlibdoc.who.int/hq/2002/a74580.pdf Accessed 20 November 2005

${ }^{14}$ Schulz III JT, Tompkins RG, Burke JF. Artificial skin. Annual Review of Medicine 2000; 51: 231-244

${ }^{15}$ Cahn F. Review: Technologies and characteristics of tissue-engineered skin substitutes. The Journal of Regenerative Medicine 2000; 1 (12): 145-155

16 Food and Agricultural Organization Statistical Database (FAOSTAT) http://faostat.fao.org/faostat/ Last updated March 2005

17 Kuta DD. GM technology to benefit farmers in Nigeria. AgBiotechNet ${ }^{\circledR} 2004$; 6 February, ABN 120. Available at http://www.agbiotechnet.com/reviews/Database/feb04/html/ABN120.htm

18 Diouf J. In The State of Food and Agriculture 2003-2004. Food and Agricultural Organization of the United Nations

19 Raney T. Agricultural biotechnology: meeting the needs of the poor? In The State of Food and Agriculture 2003-2004. Food and Agricultural Organization of the United Nations

${ }^{20}$ Lehmann V. Bioremediation: A solution for polluted soils in the South? Biotechnology and Development Monitor 1998; (34):12-17

${ }^{21}$ Wong J, Quach U, Thorsteinsdottir H, Singer PA, Daar AS. South Korean biotechnology-a rising 
industrial and scientific powerhouse. Nature biotechnology, December 2004; 22 (Supplement):DC42 47

${ }^{22}$ Kumar NK, Quach U, Thorsteinsdottir H, Somsekhar H, Daar AS, Singer PA. Indian biotechnologyrapidly evolving and industry led. Nature biotechnology December 2004; 22 (Supplement):DC31 - 36

${ }^{23}$ Motari M, Quach U, Thorsteinsdottir H, Martin DK, Daar AS, Singer PA. South Africa-blazing a trail for African biotechnology. Nature biotechnology, December 2004; 22 (Supplement):DC37 - 41

${ }^{24}$ USAID launches Nigeria Agricultural Biotechnology Project. The United States Diplomatic Mission to Nigeria Press release May 4 2004. Available at http://usembassy.state.gov/nigeria/wwwhp050404a.html 25 Nigerian government supports biotechnology initiative. International Centre for Trade and Sustainable Development, Geneva. Trade BioRes 2004; 4(9). Available at http://www.ictsd.org/biores/04-05-14/story3.htm

${ }^{26}$ Riazuddin S, Nasim A. Future growth in biotechnology in the developing countries. Genome 1989;31(2):1042-5

27 Schleicher A. Food Crisis in Zambia. PBS, posted December 2, 2002. Available at http://www.pbs.org/newshour/extra/features/july-dec02/zambia.html

${ }^{28}$ Ogodo O. Africa's dilemma: the GM struggle. Checkbiotech, posted August 10, 2005. Available at http://www.checkbiotech.org/root/index.cfm?fuseaction=news\&doc id $=10972 \&$

start $=1 \&$ control $=227 \&$ page_start $=1 \&$ page_nr $=101 \& p g=1$ 